\title{
PSICODRAMA E ATIVIDADES LÚDICAS NA PROMOÇÃO E PREVENÇÃO DA SAÚDE MENTAL INFANTIL
}

\author{
Psychodrama and Luddic Activities in the Promotion and Prevention of Children's Mental \\ Health
}

Psicodrama y Actividades Lúdicas en la Promoción y Prevención de la Salud Mental Infantil

LucylaKésia de Carvalho Silva

Universidade de Brasília

Elisa Alves da Silva

Faculdade Estácio de Sá de Goiás

\begin{abstract}
RESUMO
Este estudo tem por objetivo demonstrar a promoção da saúde mental infantil a partir da abordagem psicodramática e de recursos lúdicos. Trata-se de um relato de experiência com método qualitativo, a partir da realização de um grupo terapêutico de cinco crianças com idades de 10 e 11 anos, no período de abril a setembro de 2017. O grupo foi realizado no Serviço de Psicologia Aplicada da Faculdade Estácio de Sá de Goiás, em Goiânia-GO. Os resultados demonstraram que as atividades lúdicas e o aporte teórico da abordagem psicodramática favoreceram que as crianças reconhecessem os sentimentos e descrevessem comportamentos e eventos importantes do cotidiano que vivenciavam.
\end{abstract}

Palavras-chave: Psicodrama; Atividades lúdicas; Promoção e Prevenção; Saúde mental infantil.

\begin{abstract}
This study aims to demonstrate the promotion of children's mental health from the psychodramatic approach and ludic resources. This is an experience report with a qualitative method, in which therapeutic group of five children between the ages of nine and twelve years was carried out from April to September 2017. The group was carried out in the Service of Applied Psychology of Faculdade Estácio de Sá de Goiás, Goiânia-GO. The results showed that ludic activities and the theoretical contribution of the psychodramatic approach favored the children to recognize the feelings and to describe behaviors and important events of the daily life that they lived.
\end{abstract}

Keywords: Psychodrama; Ludic activities; Promotion and Prevention; Children's mental health. 


\section{RESUMEN}

Este estudio tiene como objetivo demostrar la promoción de la salud mental infantil a partir del abordaje psicodramático y de actividades lúdicas. Se trata de un relato de experiencia con método cualitativo en el que se realizó de un grupo terapéutico de cinco niños con edades entre nueve y doce años en el período de abril a septiembre de 2017. El grupo fue realizado en el Servicio de Psicología Aplicada de la Facultad Estadio de Sá de Goiás, en Goiânia-GO. Los resultados demostraron que las actividades lúdicas y el aporte teórico del abordaje psicodramático favorecieron que los niños reconocier los sentimientos y describir comportamientos y eventos importantes de lo cotidiano que vivían.

Palavras Claves: Psicodrama; Actividades lúdicas; Promoción y Prevención; Salud mental infantil.

\section{INTRODUÇÃO}

A fase da infância tem um papel fundamental na vida de qualquer pessoa e tudo que se vivencia nela contribui para o processo de formação do adulto, pois remetem aos períodos de desenvolvimento físico, emocional e cognitivo. Para que uma criança possa desenvolver-se saudavelmente em cada etapa é necessário um ambiente seguro que possa proporcionar acolhimento, respeito e atenção em todas as demandas (Sinibaldi, 2013).

No Brasil, muitas crianças não vivem essa realidade e estão expostas diariamente a situações de negligência, vulnerabilidade e privação múltipla, ou seja, tem um ou mais direitos negados (UNICEF, 2008). Algumas famílias encontram-se em circunstâncias críticas, como: discórdia conjugal severa, dificuldades na renda, tamanho grande da família, criminalidade paterna, abuso de álcool e/ou outras drogas, e ,muitas vezes, não conseguem proporcionar condições saudáveis aos membros menores (Bethel et al., 2017).

Há também famílias que se encontram em vulnerabilidade subjetiva, tendo assim uma incapacidade de gerir os recursos de forma equilibrada. Esses tipos de desestruturações familiares consequentemente repercutem na vida das crianças (Costa Moreira, Brendan, \& Dojas, 2011). São situações que além de prejudicar o processo de desenvolvimento, em qualquer aspecto, podem gerar significativos problemas mentais, transtornos de conduta e dificuldades de aprendizagem (Sinibaldi, 2013).

Nesse contexto, os transtornos mentais estão entre as cinco principais causas de doenças infanto-juvenis no mundo. Estima-se que 10 a $20 \%$ dessas crianças apresentam alguma psicopatologia (Assis, Avanci, \& Oliveira, 2009). Pesquisas afirmam que as crianças estão expostas a inúmeros fatores ambientais que podem desencadear problemas emocionais, sociais e de comportamento (Assis et al., 2009; Halpern, \& Figueiras, 2004). É essencial estar atento para as necessidades da infância e identificar fatores de riscos que estão associados as psicopatologias (Freitas, \& Ferret, 2013). 
E tão necessário quanto identificar os fatores de risco, reconhecer os fatores de proteção. Os fatores de proteção são recursos pessoais ou sociais que amenizam ou inibem o impacto do risco e contribuem para uma infância mais saudável. Pesquisas relatam que a consciência da potencialidade dos fatores de risco e proteção existentes é primordial para o desenvolvimento de ações preventivas e para evitar a disfunção mental (Bellis et al., 2018). Nesse sentido, considera-se importante a busca por ferramentas que estimulem as crianças a expressarem suas emoções e a reconhecerem seus recursos internos e sociais que as ajudem em situações de risco.

Existe atualmente, principalmente por parte da Organização Mundial de Saúde (OMS), uma preocupação em atenção à saúde quando se trata do nível de prevenção. Um dos objetivos dos planos de ações da OMS para saúde mental até 2020 é a implementação de estratégias e programas multi-setoriais que promovam e previnam os transtornos mentais (Mental Health Atlas, 2017).

A importância dessas ações são principalmente pelos impactos negativos emocionais e sociais oriundos dos transtornos mentais. Na infância e adolescência esses impactos tornam-se ainda mais graves, pois podem gerar efeitos que dificulta a fase de desenvolvimento, afetando a capacidade criativa e a inserção social desses indivíduos quando adultos (Pacheco, Campos, Barbosa, Alves, \& Fernandes, 2017).

E um outro aspecto que está intrinsecamente ligado ao anterior, é o impacto econômico causado por esses transtornos. No Brasil, por exemplo, no ano de 2011 foram investidos mais de 525 milhões de reais com hospitais psiquiátricos. Esse impacto econômico faz com que se pense mais sobre o aspecto de prevenção, não só em termos de eficácia na promoção da saúde mental, mas também pelo aspecto de menor custo que a prevenção oferta (Brasil, 2015).

Pode-se dizer que as intervenções preventivas têm por objetivo diminuir a incidência e a prevalência de transtornos mentais, seja evitando o surgimento, seja minimizando o agravamento (Abreu, Barletta, \& Murta, 2015). E nesse sentido, "ainda que intervenções preventivas e promotoras de saúde mental sejam recomendáveis ao longo de todo um curso de vida, o período da vida em que as ações preventivas devem ter o maior foco é na infância e na adolescência" (Murta, Gunther, \& Guzzo, 2015, p. 82).

Entre as várias possibilidades de promover a saúde mental infantil, as atividades lúdicas têm sido utilizadas como uma terapêutica enriquecedora na vida das crianças (Phillipini, 2008). O processo criativo, envolvido no contexto lúdico, estimula a criança a desenvolver autoestima, autonomia, sentimento de empatia e a adquirir pensamentos mais flexíveis (Barbosa, 2005).

O uso do lúdico como recurso terapêutico é um processo predominantemente de linguagem não verbal. A dança, a dramatização, a pintura e as artes plásticas são meios de 
acolher o ser humano em toda sua complexidade. Dentre as práticas lúdicas, há também as atividades artísticas que estimulam as crianças a criarem representações simbólicas do cotidiano e propiciam contato com o mundo interno (Coqueiro, Vieira, \& Freitas, 2010).

Nessa perspectiva, têm-se o psicodrama como aporte teórico a esses tipos de intervenções terapêuticas, abordagem psicológica que tem sido muito utilizada no contexto preventivo e de promoção a saúde por ser um trabalho ativo e também criativo. Essa abordagem postula que o indivíduo nasce com recursos inatos: espontaneidade, criatividade e sensibilidade, que são responsáveis por impulsionar o homem ao crescimento (Baptista, 2012).

Segundo Baptista (2012), Filipini (2014) e Gonçalves (1988), o conceito de saúde mental na teoria psicodramática é a capacidade de desenvolver e inverter papeis sociais. Esses papeis são criados a partir do contexto social em que o sujeito vive, possibilitando explorar a forma como o ser humano age no mundo. Então a abordagem se objetiva em propiciar um espaço para que o paciente compreenda melhor as características do seu funcionamento e em quais situações essas características são desadaptativas.

No trabalho com crianças, o psicodrama tem como foco oferecer condições para o surgimento de novos papeis e fortalecer os que estão pouco desenvolvidos ou mal estruturados. É necessário um relacionamento de respeito e liberdade ao potencial criativo de cada criança para que ela se sinta acolhida e segura (Gonçalves,1988).

No contexto grupal, a abordagem psicodramática surge como meio de gerar autoconhecimento para as crianças a partir da relação entre pares (Castro \& Almeida, 2017). Em grupo, a criança passa a ter o outro como referência significativa no processo de confirmação dos recursos pessoais e sociais (Baptista, 2012). Dessa forma, incluir as práticas lúdicas e a abordagem psicodramática no contexto grupal contribui para estimular a criatividade e o potencial infantil. Nas manifestações simbólicas por meio da vivência lúdica, a criança é motivada a evocar acontecimentos não elaborados e ressignificá-los (Alexandroff, 2010).

Diante disso, esse estudo tem enquanto relevância acadêmica e social, o intuito de produzir relações entre o lúdico, o psicodrama e a saúde mental infantil e auxiliar na assistência a prevenção e promoção no campo da infância. Para tanto, esse estudo tem como intuito apresentar o relato de experiência realizado por meio do estágio supervisionado em psicologia, que teve como objetivos demonstrar o recurso lúdico e a aborgagem psicodramática atuantes como ferramentas terapêuticas na promoção e prevenção da saúde mental infantil. 


\section{MÉTODO}

De acordo com os objetivos traçados, trata-se de um estudo descritivo, tipo relato de experiência, que foi realizado no método de abordagem qualitativa que visa compreender os fenômenos que não podem ser mensurados (Tartuce, 2008). De acordo com Minayo (2007, p. 57), "[...] as abordagens qualitativas se conformam melhor a investigações de grupos e segmentos delimitados e focalizados".

O relato de experiência refere-se a uma modalidade de gênero textual, de ordem expositiva, descritiva e argumentativa, no qual os pesquisadores irão relatar um estudo de caso com o objetivo de elucidar aplicações clínicas (American Psychology Association, 2012). $O$ relato desta experiência trata-se das atividades desenvolvidas em um grupo terapêutico durante o estágio obrigatório supervisionado do curso de Psicologia na Faculdade Estácio de Sá de Goiás.

Para realizar o relato de experiência, foi utilizado como instrumento de coleta de dados o diário de campo preenchido pelos pesquisadores. Segundo Minayo (2007), o diário de campo é um instrumento que registra todas as informações relevantes que ocorrem durante a experiência, estabelecendo conexão com os objetivos traçados e as observações sobre as conversas, gestos, comportamentos e expressões que digam respeito ao tema investigado. Assim, em todo término dos encontros, eram elaborados os diários de campo que foram apresentados na supervisão de estágio.

Dessa forma, foi organizado um grupo terapêutico (conforme Quadro 1) com cinco crianças que tinham entre 10 e 12 anos. Inicialmente foram realizadas entrevistas com seis crianças e seus responsáveis, porém, uma das crianças não frequentou mais o grupo e os responsáveis não justificaram a ausência. O critério de participação foi que essas crianças estivessem na lista de espera para atendimento psicológico disponibilizada no Serviço de Psicologia Aplicada (SPA), da Faculdade Estácio de Sá de Goiás, em Goiânia-GO e que pudessem participar dos grupos semanais que ocorriam aos sábados pela manhã. Para preservar o anonimato dos participantes serão usadas siglas representativas, sendo assim denominadas: 
Quadro 1:

\begin{tabular}{|c|c|c|}
\hline Participantes/Sexo & Idade & \multicolumn{1}{|c|}{ Queixas relatadas pelos responsáveis } \\
\hline GN/ Masculino & 10 ANOS & Ansiedade após a separação dos pais. \\
\hline GW/ Masculino & 10 ANOS & Autoestima baixa, insegurança, dificuldades na leitura. \\
\hline BL/ Feminino & 12 ANOS & $\begin{array}{l}\text { Autoestima baixa, rebelde, dificuldade } \\
\text { aprendizagem e dificuldade de interagir com outras } \\
\text { meninas. }\end{array}$ \\
\hline MS/ Feminino & 11 ANOS & $\begin{array}{l}\text { Dificuldade de aprendizagem e ciúmes patológico } \\
\text { direcionado na relação da mãe com o padrasto. }\end{array}$ \\
\hline AC/ Feminino & 11 ANOS & $\begin{array}{l}\text { Mente, desobedece, tem muito } \\
\text { argumentação. }\end{array}$ \\
\hline
\end{tabular}

Fonte: autoras do artigo.

Antes de iniciar o grupo terapêutico, foi realizado um encontro com os responsáveis das crianças para levantar a demanda relacionada a busca pelo atendimento no SPA, esclarecido sobre os objetivos do grupo terapêutico e o interesse e autorização dos mesmos para que a criança pudesse participar do grupo. Depois de finalizado o grupo terapêutico, foi feito novamente outro encontro com os responsáveis com o objetivo de averiguar se houveram mudanças nos comportamentos dos integrantes. Os encontros com os responsáveis foram individuais.

Ocorreram nove encontros como grupo terapêutico, acontecido uma vez por semana, aos sábados, durante os meses de abril a setembro de 2017 , tendo férias no período de julho. Os encontros tiveram uma hora e trinta minutos de duração e aconteceram no Laboratório de Observação (LOB) do SPA da Faculdade Estácio de Sá de Goiás.

O primeiro encontro teve como objetivo a apresentação dos coordenadores e dos participantes, o contrato, a escolha dos temas que os participantes desejavam que fossem trabalhados e o início da formação do vínculo terapêutico. Os demais encontros foram compostos por três momentos: o lúdico, o de criação artística sendo finalizado com o momento de compartilhamento. Cada encontro teve atividades relacionadas aos temas que foram escolhidos no primeiro encontro pelos participantes. Os temas foram: mudança de ambiente escolar, amizades complicadas, não gostar de estudar, sentimentos de raiva, relacionamento com os irmãos, e relacionamento com os pais.

Os participantes e responsáveis foram esclarecidos verbalmente e por escrito a partir do Termo de Consentimento Livre e Esclarecido (TCLE) e Termo de Assentimento para 
Menores, que os alunos-pesquisadores se comprometeram às normas de confidencialidade e de sigilo profissional, fazendo o compromisso em não fazer identificações particulares, garantindo o sigilo e a privacidade. Uma vez esclarecidos todos os procedimentos da pesquisa e as questões do contrato terapêutico, os responsáveis e seus participantes assinaram o TCLE e o Termo de Assentimento para menores.

\section{RESULTADOS E DISCUSSÃO}

No primeiro encontro do grupo compareceram cinco crianças. Os coordenadores se apresentaram e conversaram sobre os objetivos do grupo. $\mathrm{Na}$ apresentação dos integrantes foi utilizada uma técnica lúdica em que eles escolhiam figuras para se apresentarem. As figuras eram relacionadas a família, animais, crianças, desenho animado e figuras abstratas. A apresentação contemplou o nome, a idade e o motivo que eles se identificavam com as figuras que escolheram. Demostraram nesse primeiro momento timidez e pouca interação entre os membros.

Depois foi feito a escolha de temas que eles tinham vontade de trabalhar nos encontros subsequentes. Foram sugeridos alguns temas-chaves pré-estabelecidos pelos coordenadores, como: família, escola, emoções, autoestima e comunicação. Esses temas foram escolhidos a partir das queixas trazidas pelos pais no encontro inicial. Os temas foram expostos na cartolina, e os participantes trouxeram temas, que gostariam de abordar, que foram: mudança de ambiente escolar, amizades complicadas, não gostar de estudar, sentimentos, raiva, relacionamento com os irmãos, relacionamento com os pais, habilidades.

Eles foram convidados a escrever esses temas em uma cartolina. Nesse momento foi notado maior interação e integração entre o grupo. As interações são importante nesse processo, pois segundo Fleury e Marra (2008), na visão psicodramática, é o primeiro modo de integrar o indivíduo às forças grupais e favorecer a aproximação recíproca, cujo o maior objetivo é o auxílio mútuo oferecido aos participantes do grupo.

Posteriormente foi conversado sobre o contrato terapêutico, feito por meio de colagem. Foram ressaltadas questões de sigilo, falta no grupo e devolutiva com os pais. Houve interação e demonstração de interesse. O grupo foi finalizado com uma música, e foi pedido para que os integrantes andassem pela sala e observassem as sensações corporais. Depois foi compartilhado quais foram os sentimentos que vieram. Todos relataram que sentiram vergonha, porém com expressões de alegria.

Essas interações confirmam que os recursos lúdicos criam oportunidades para que as crianças elaborem significados para objetos, pessoas, situações e interações (Filipini, 2014). As atividades lúdicas é um modo criativo de interação social para a autonomia. Ao convidar os participantes a falarem de suas demandas, os colocamos como protagonistas das 
suas histórias. Essa prática permite à criança desenvolver o contato com o mundo social e reinventá-lo, transformá-lo e internalizá-lo.

No segundo encontro, estavam presentes quatro crianças. Neste dia foi falado sobre o tema identidade e realizou-se uma atividade de criação de crachás. Como o foco do grupo era de promover saúde mental, os temas gerais que nomeavam os encontros tinham o objetivo de nortear o que emergiu como tema de interesse pelos participantes no primeiro encontro. O objetivo de trabalhar com o tema identidade foi criar um crachá de características que os integrantes achavam importantes e que julgavam fazer parte da identidade. Desenharam nos crachás dados que os identificavam como idade, sobrenome, escola e coisas que gostavam, como música, moda e esportes.

No Psicodrama, a identidade não é algo estático ou pronto, é formada em um processo de desenvolvimento humano e fundado na matriz de identidade que é um dos pilares da abordagem. Com esse conceito, o criador do psicodrama, Moreno, quer estabelecer a ideia de que há um processo de inter-relações que dá origem às qualidades e características humanas (Fator, 2010).

Trabalhar a identidade no grupo permitiu que as crianças entrassem em contato com suas crenças, características e com o meio em que vivem. Foi possível averiguar que o autoconhecimento promove saúde mental a medida que as crianças se dão conta dos seus recursos internos (Bellis et al., 2018). BL, por exemplo, disse que quando escuta um música no estilo que gosta como, por exemplo, rap, se sentia mais feliz. MS se identificou com o relato de $\mathrm{BL}$ e reconheceu a atitude como uma prática também utilizada por ela para ter momentos felizes.

Esses resultados demonstraram que a exploração do autoconceito nas crianças tem um impacto positivo, pois, ao descobrirem seus recursos pessoais podem ter auto-suporte em momentos difíceis. Estudos relara que o auto-suporte atua como fato de prevenção à saúde mental e contribui no desenvolvimento da resiliência (Cunha, \& Rodrigues, 2010; Oliveira, \& Nakano, 2011). A resiliência auxilia a criança a encontrar as respostas mais eficazes e soluções mais adaptadas na presença de um ambiente desfavorável (Oliveira, \& Nakano, 2011).

Logo após foi feita uma técnica de fantasia, foi contada uma história enquanto as crianças permaneciam deitadas, relaxadas e ao fecharem os olhos imaginavam essa história. Ao final da história, as crianças chegam em uma porta, que ao abrir, iriam ver o "Seu lugar". Depois foi solicitado que eles desenhassem o que viram ao final da fantasia (o lugar). Após eles compartilharam sobre seus desenhos, os participantes relataram sentimentos como paz e leveza.

Conforme visto nos desenhos e apontado por Oaklander (1980), são comuns as cenas de fantasia representadas pelas crianças. E também com frequência as crianças 
representam cenas que se encontram em oposição direta aos seus sentimentos. Por meio da fantasia foi possível ter acesso àquilo que é oculto da criança, sabendo o que se passa na vida dela, a partir da visão da própria criança, por isso é importante encorajar o uso da fantasia e usá-la como recurso terapêutico.

Nas fantasias a criança é convidada a nomear os sentimentos e emoções associados a suas experiências reais. Essas intervenções auxiliam as crianças a ressignificarem situações-problemas e, consequentemente, contribui para o alívio de sofrimentos psíquicos (Baptista, 2012). Desse modo, as intervenções psicológicas são práticas que visam ajudar as crianças e os grupos a entender e fortalecer os fatores que permitem a redução da incidência e a prevenção de psicopatologias que surgem das condições de vida adversa (Oliveira, \& Nakano, 2011).

O terceiro encontro iniciou-se com quatro participantes. Nesse dia foi falado sobre a autoestima e a importância deste tema na vida das pessoas. Segundo Briggs (2002), desenvolver a autoestima faz com que a criança cultive um sentimento de auto respeito e reconhecimento do próprio valor. Nesse sentido, foi solicitado que as crianças apontassem aquilo que gostavam em si, e que viam como qualidade. $E$ também aquilo que não gostavam e queriam mudar, ou que deveriam aprender a aceitar. Alguns tiveram dificuldades de apontar aquilo que gostavam em si. Observou-se que os integrantes estavam à vontade e refletiram sobre o assunto.

Houve a continuidade e foi realizada a técnica da bandeira (Serrão, \& Baleeiro, 1999) momento em que foram feitas perguntas e cada criança respondeu com um desenho que representasse a resposta. As perguntas eram relacionadas ao que eles gostavam de fazer e o que eles gostavam ou não em si. Eles responderam com desenhos relacionados à família e aos amigos, e responderam sobre si coisas relacionadas aos seus aspectos físicos. Nesse momento, todos compartilharam as descobertas sobre si e sobre o outro.

Em seguida, foi realizada outra técnica em que os coordenadores entregaram uma caixa para todas as crianças e informaram que havia a imagem da pessoa mais importante da vida deles (havia um espelho na caixa). Ao receberem a caixa eles se divertiram muito, inclusive com gargalhadas da parte de todos. Ao final, foi solicitado que cada um dissesse algo bom para aquela pessoa mais importante. Observou-se que eles tiveram dificuldades de expressarem algo para eles mesmos. Foi sugerido que eles pensassem sobre isso no decorrer da semana.

Essas atividades demonstram o lúdico como uma estratégia para a construção do autoconhecimento e permite que o mesmo se desenvolva tanto individualmente como coletivamente (Ramalho, 2000). No que tange as práticas preventivas, Cunha e Rodrigues (2010) afirmam que a promoção da autoestima está incluída no conjuntos de ações que visam 
reconhecer as competências e capacidades de cada criança. Desenvolver a autoestima é também considerada uma estratégia para neutralizar os efeitos dos fatores de risco.

No quarto encontro estavam presentes três integrantes, foi realizada uma técnica de apresentação em que cada participante foi convidado a apresentar o indivíduo à sua direita com o nome e uma qualidade que observou nele. Foram utilizadas qualidades como, inteligente, comunicativa e confidente. Nesta atividade lúdica a criança é convidada a voltar-se para o outro, assim como na matriz de identidade na concepção psicodramática, que existe a fase do reconhecimento do Tu, estágio no qual o indivíduo passa a perceber não só a si, mas, também, percebe o outro (Fonseca, 2012).

Foi apresentado também um vídeo sobre convivência falando de situações de rejeição e aceitação, no qual as crianças foram questionadas sobre com quem se identificavam, com o personagem rejeitado ou os personagens que rejeitavam. $\mathrm{Na}$ maior parte, se consideraram o grupo que rejeita. Logo após, foi feita uma dinâmica de desenho compartilhado, em que cada criança começa um desenho em um papel e quando solicitado, passa esse desenho para que outro colega continue. Foi percebido espontaneidade e criatividade ao continuarem o desenho do outro. Ao final foram questionadas sobre como se sentiram continuando o desenho do colega, disseram ter se sentido insegurança e logo após, conforto.

O quinto encontro do grupo iniciou com a presença de todos os integrantes. Após um momento de acolhimento os coordenadores falaram sobre o tema: comunicação e a consequência de sua falha. De acordo com Manzini (2001), a importância da comunicação é a troca de informações, sensações e sentimentos. Para o autor, desenvolver uma comunicação assertiva e verdadeira oferta a criança recursos que melhoram suas interações.

Depois os coordenadores mostraram um vídeo de animação sobre comunicação diretiva, que mostrou a importância de falar o que realmente quer que o outro ouça. Foi aberto um debate sobre o tema. Após, foi pedido que eles colocassem em um papel o que eles não gostavam de ouvir das pessoas e posteriormente que eles transformassem essas frases em algo que eles gostariam de ouvir. Foi trabalhado com cada um a dramatização dessas frases e como eles responderiam de acordo com o que foi conversado sobre comunicação diretiva e verdadeira.

Todos participaram e interagiram. Surgiram temas como bullying na escola, relacionamentos com os pais e amigos. Segundo Baptista (2012), para o psicodrama as dramatizações em um momento faz-de-conta favorecem a espontaneidade, a criatividade e permitem que a criança elabore ou ressignifique situações que não foram elaboradas ou que tragam algum sofrimento psíquico. Após isso, no grupo foi compartilhado como foi para os integrantes responderem de outro jeito o que eles não gostavam de ouvir. Eles deram o nome dessa nova comunicação de "evitar tretas". Foi feito um relaxamento e o grupo foi encerrado. 
Ao final do encontro, foi possível perceber que a dramatização como ferramenta lúdica colabora para o conhecimento do meio em que a criança se encontra inserida, pois no ato de dramatizar ela se comunica consigo mesmo e com o outro. Essa atividade ajuda nas diferentes formas de linguagem, proporcionam um senso crítico, contribui para uma boa saúde mental e permite que a criança perceba novas possibilidades (Figueiredo, 2008).

O sexto encontro teve a participação de três integrantes. Foi dedicado a falar da importância da identificação e expressão das diversas emoções. Em uma das atividades as crianças deveriam identificar as emoções que estavam desenhadas ligando-as a sua descrição. Em outro momento foi solicitado que as crianças desenhassem algumas emoções e descrevessem quando elas acontecem em sua vida. As emoções utilizadas foram de alegria, medo, raiva e tristeza. Em seguida todos compartilharam com o grupo quando e o por que sentiam essas emoções.

Conforme Janiro (2005), trabalhar emoções com crianças é fundamental, pois quando as crianças reconhecem as emoções, têm mais facilidade para lidar com elas, principalmente quando se tratam de emoções ruins. É o início de um processo de inteligência emocional e que pode auxiliar na prevenção e promoção em saúde mental.

O sétimo encontro, aconteceu depois das férias, e iniciou com todos participantes. Inicialmente houve um acolhimento de boas-vindas, na qual os integrantes contaram sobre como haviam sido as férias. Posteriormente, falou-se sobre a atividade do dia que foi pintar uma tela livremente com tinta guache, pois "a pintura possui seu próprio valor terapêutico especial" (Oaklander,1980, p.62). Para que eles entrassem em contato com o mundo interno, foi sugerido um momento de respiração. Nesse momento, os participantes não conseguiram iniciar, pois ficavam rindo e de olhos abertos. Eles estavam agitados.

Então foi entregue o material e eles iniciaram a pintura. Houve interação, troca de material, elogio aos desenhos uns dos outros e criação de cores novas. Foi pedido que eles dessem um nome para o que eles pintaram e compartilhassem sobre as pinturas. Trabalhos originais e muito coloridos resultaram desse processo. Algumas crianças deixaram expressar os sentimentos na tela com muita clareza. No final foi percebido que eles estavam relaxados e contentes.

Nessa atividade percebeu-se que o processo de criação artística são meios lúdicos que demonstram o quanto as crianças falam de si, de seu mundo, de suas ideias por meio das obras que criam. Essas atividades também propiciam o desenvolvimento da criatividade e espontaneidade, liberando-as em outras áreas da vida (Coqueiro, Vieira \& Freitas, 2010).

No oitavo encontro, apenas o GW esteve presente. Iniciou-se uma conversa sobre como ele estava se sentindo por estar sozinho com os coordenadores. Ele relatou que quando tem mais crianças ele se sente mais seguro, demonstrando o quanto o grupo oferta 
a ele segurança e confiança. Então, após a conversa, foi solicitado que ele pensasse nas características que ele admira na família dele. Posteriormente foi passada uma atividade em que ele tinha que modelar essas características. Ele criou os olhos da sua mãe, o cabelo branco do avô e um traço fino para a figura do pai. Nesse momento ele se emocionou. Foi feito acolhimento a emoção da criança e depois ele criou um traço forte e grosso e afirmou ser o braço do irmão. Após, GW compartilhou sobre todas as características criadas.

Na técnica de imagem da família da ludoterapia, a criança cria uma imagem dos elementos da família com os recursos disponíveis e é solicitado que a criança fale sobre essa construção. Isso proporciona a exploração e conscientização dos sentimentos da criança pela família (Brito, \& Freire, 2014).

O último encontro iniciou com a presença de quatro participantes e teve como objetivo avaliar com os integrantes as possíveis mudanças que haviam notado. Eles chegaram alegres e motivados. Os coordenadores falaram sobre o encerramento e foi relembrado os temas que foram trabalhados nos encontros anteriores. Os participantes, interagiram e falaram sobre seus aprendizados. Depois os coordenadores entregaram uma ficha de avaliação dos encontros. Vale esclarecer, que a avaliação com a integrante AC foi feita individualmente, pois a mesma faltou.

Eles responderam perguntas sobre o que aprenderam, o que foi importante no aprendizado, como se sentiram, o que gostaram e o que não gostaram, sobre as relações com as pessoas do grupo e o que esperavam do futuro. Nas respostas dos integrantes foram observados autoconhecimento, percepção dos comportamentos e sentimentos no decorrer dos encontros e a expressão da subjetividade de forma espontânea.

Nesse contexto, GN comentou que aprendeu a não ficar dando "murro na parede" e que acha importante não dar trabalho para a mãe. ML relatou estar muito contente, pois aprendeu a trabalhar em grupo, algo que antes achava difícil, e que muitas lembranças do grupo iriam ficar na memória. BP disse que aprendeu que é preciso evitar "treta", e o quanto é importante a autoestima e que, mesmo quando ia emburrada para o grupo por ter que acordar cedo, se sentia bem quando estava no grupo. GW explicou que o grupo mostrou pra ele a como respeitar as pessoas, e que ele gostou muito de ter participado porque conseguiu liberar a tristeza e que por isso quer continuar indo ao psicólogo. AC verbalizou o que ela mais gostou no grupo foi aprender a controlar a raiva e se sentir mais leve.

Após esse momento, houve uma técnica lúdica de despedida chamada "dizendo adeus", na qual os participantes escolheriam alguém para expressar com um gesto o que fosse indicado pelo coordenador. Eles escolheram quem Ihe deram boas vindas, quem era diferente deles, quem podia ser chamado de amigo e quem foi a revelação do grupo. Nessa técnica houve interação e descontração. Segundo Serrão e Baleeiro (1999), essa técnica tem 
como objetivo possibilitar a finalização dos encontros e sugerir que as crianças expressem os sentimentos referentes ao grupo.

Depois foi passado um curta-metragem que trouxe a vivência de um passarinho na busca por seu primeiro alimento e os desafios que ele tinha que enfrentar. Após este momento o grupo compartilhou sobre seus medos e as sensações que eles sentiam quando iam fazer algo pela primeira vez. Eles trouxeram situações como: o primeiro dia na escola nova, viajar de avião, conhecer pessoas e as vezes não saber lidar com a desobediência aos pais. Depois falaram como sentiram após superarem essas situações. Por fim, cada participante deixou uma mensagem de despedida aos colegas do grupo e este foi encerrado.

Com o encerramento do grupo terapêutico, foi realizado um encontro com cada responsável, cujo o objetivo foi avaliar quais mudanças foram percebidas a partir das queixas trazidas. Os pais relataram que as crianças melhoraram o relacionamento interpessoal, tiveram melhor desempenho na escola, a mãe de GN e GW relataram o comprometimento e a felicidade dos filhos em estarem presentes nos encontros. Outras mães relataram que apesar da falta de motivação de alguns para irem aos encontros pelo motivo de ser sábado pela manhã, as crianças saiam do grupo felizes. A mãe da $A C$ relatou que a filha parou de contar mentiras e que ficava entusiasmada para ir aos encontros.

Conforme observado em todos os encontros, as atividades lúdicas e o aporte teórico da abordagem psicodramática, favoreceram uma melhor compreensão do meio em que a criança está inserida. Além de proporcionarem que as crianças informassem sobre os sentimentos e descrevessem comportamentos e eventos importantes. A partir das estratégias relatadas foi possível formar e consolidar o vínculo entre os coordenadores e as crianças.

Essas estratégias também possibilitaram as relações das crianças com as pessoas dos ambientes em que estão inseridas, a identificação dos sentimentos da criança em relação a si mesma e a determinadas pessoas e situações. Também permitiu que as crianças olhassem para novas possibilidades na solução de problemas cotidianos por meio de situações dramatizadas, trabalhou a autoconfiança da criança e favoreceu o relaxamento.

Os fundamentos do psicodrama Moreniano contribuíram na compreensão da espontaneidade, da criatividade e ajudou a propiciar um ambiente em que as crianças compreendessem melhor as características do comportamento, facilitando 0 autoconhecimento. Nessa perspectiva, foi observado que tanto o setting grupal como as estratégias lúdicas e psicodramáticas utilizadas, criaram condições que desenvolveram fatores de proteção nas crianças, estabelecendo promoção e prevenção da saúde mental.

\section{CONSIDERAÇÕES FINAIS}

Por meio dessa investigação foi possível verificar que o objetivo da promoção e prevenção da saúde mental é de identificar e atuar sobre determinantes que influenciam nos 
processos de saúde/doença. Nesse contexto, a partir dessa experiência, foi possível observar que as atividades lúdicas são ferramentas que auxiliam na identificação desses determinantes de forma espontânea e criativa. O uso do lúdico leva a criança a entrar em contato consigo e a olhar para possibilidade de criar novos respostas à situações de risco.

O psicodrama, por ser um método ativo e intimamente ligado ao trabalho com grupos, contribuiu para que os coordenadores identificassem os movimentos dos participantes e favorecerem a liberdade do contexto grupal de forma espontânea e criativa. Com o vínculo, o acolhimento, as observações dos desenhos, dos compartilhamentos, dos jogos e avaliações, foi visto o desenvolvimento da espontaneidade-criatividade.

Durante os encontros, apesar da realização do contrato terapêutico, a dificuldade esteve relacionada a quantidade de faltas dos participantes visto que na maior parte dos encontros, não estavam todos presentes. Nos encontros semanais, por ocorrerem aos sábados pela manhã, notava-se muitas vezes nos participantes logo nos momentos inicias o desânimo e apatia, pois, para alguns, participar do grupo era visto como uma obrigação imposta pelos pais; apesar de saírem satisfeitos.

Acrescenta-se que o estudo ofereceu a experiência de perceber como essas atividades podem causar um impacto favorável na vida das crianças. Além de fazer um paralelo entre a clínica, o social e a prática; contribuindo para formação do papel do profissional enquanto realização do estágio, e facilitando na prevenção e na promoção da saúde mental infantil.

\section{REFERÊNCIAS}

American Psychological Association (2012). Manual de publicação da American Psychological Association. (6a ed.). Porto Alegre: Penso.

Abreu, S., Barletta J. \& Murta, S. (2015). Prevenção e promoção em saúde mental: pressupostos teóricos e marcos conceituais. In: S. G. Murta, C. Leandro-França, K. B. Santos, \& L. Polejack (Eds). Prevenção e promoção em Saúde Mental. (pp. 54-74). Novo Hamburgo: Sinopsys.

Alexandroff, M. C.. (2010). Os caminhos paralelos do desenvolvimento do desenho e da escrita. Construção psicopedagógica, 18(17), 20-41. Recuperado em 20 de janeiro de 2018 de http://pepsic.bvsalud.org/scielo.php?script=sci_arttext\&pid=S141569542010000200003

Assis, S. Q., Avanci, J., \& Oliveira de V. C. R., (2009). Desigualdades socioeconômicas e saúde mental infantil. Revista de Saúde Pública, 43(1), 92-100. Recuperado em 12 de março de 2018 de http://www.redalyc.org/pdf/672/67240181014.pdf

Barbosa, A.M.A. A (2005). Arte - Educação não é espetáculo. Folha Sinapse, n.34, p.16-17. 
Baptista, M. C. V. D. (2012). O palco da espontaneidade: psicodrama contemporâneo. São Paulo: Rocca.

Bethell, C. D., Carle, A., Hudziak, J., Gombojav, N., Poderes, K., Wade, R., \& Braveman, P. (2017). Métodos para avaliar as experiências adversas na infância de crianças e famílias: rumo a abordagens para promover o bem-estar da criança na política e na prática. Pediatria Acadêmica, 17(7), p. S51-S69. Doi: 10.1016/j.acap.2017.04.161

Bellis, M. A., Hughes, K., Ford, K., Hardcastle, K. A., Sharp, C. A., Madeira, S., ... Davies, A. (2018). Experiências adversas na infância e fontes de resiliência infantil: um estudo retrospectivo de suas relações combinadas com a saúde da criança e a frequência educacional. BMC Saúde Pública, 18(1), 792. Doi: 10.1186/s12889-018-5699-8

Brasil, Ministério da saúde. (2015). Saúde mental em Dados - 12, ano 10, n 12. Informativo eletrônico. Brasília. Recuperado em 27 de 10 de 2018.

http://www.mhinnovation.net/sites/default/files/downloads/innovation/reports/Report_12edicao-do-Saude-Mental-em-Dados.pdf

Briggs, D. C. (2002). A auto-estima do seu filho. São Paulo: Martins Fontes.

Brito, R. A. C., \& Freire, J. (2014). Ludoterapia centrada na criança: uma leitura a partir da ética de Emmanuel Lévinas. Revista da Abordagem Gestáltica, 20(1), 118-127.

Recuperado em 24 de janeiro de 2018, de

http://pepsic.bvsalud.org/scielo.php?script=sci_arttext\&pid=S1809-

$68672014000100015 \&$ Ing=pt\&tlng=pt

Castro, A., \& Almeida, V. (2017). O psicodrama de grupo e a ressignificação de sentimentos: o adolescente no palco. Revista Brasileira de Psicodrama, 25(1), 101-107. Doi: $10.15329 / 2318-0498.20170012$

Coqueiro, N. F., Vieira, F. R. R., \& Freitas, M. M. C. (2010). Arteterapia como ferramenta terapêutica em saúde mental. Acta Paulista de Enfermagem, 23(6), 859 862. Doi: $10.1590 /$ S0103-21002010000600022

Costa Moreira, M. I.; Bedran, P. M., \& Dojas, S. M. S. C. (2011). A família contemporânea brasileira em contexto de fragilidade social e os novos direitos das crianças: desafios éticos. Psicologia Revista. (Belo Horizonte), 17(1), 161-180. Recuperado em 13 de maio de 2018. http://pepsic.bvsalud.org/scielo.php?script=sci_arttext\&pid=S167711682011000100012

Cunha, N., \& Rodrigues, M. C. (2010). O desenvolvimento de competências psicossociais como fator de proteção ao desenvolvimento infantil. Estudos Interdisciplinares em Psicologia, 1(2), 235-248. Recuperado em 15 de dezembro de 2018, de http://pepsic.bvsalud.org/scielo.php?script=sci_arttext\&pid=S223664072010000200008\&lng=pt\&tlng=pt.

Fator, T. (2010). A Teoria psicodramática e o desenvolvimento do papel profissional. São Paulo: Universidade Municipal São Caetano do Sul. Recuperado em 20 de setembro de 2018, de http://repositorio.uscs.edu.br/handle/123456789/131

Figueiredo, A. C. Q. (2008). A ludicidade como referência na educação infantil: recurso pedagógico na aprendizagem ou forma de entretenimento? Universidade Federal de Mato Grosso do Sul/Campus de Aquidauana. Monografia de Graduação. 
Filipini, R. (2014). Psicoterapia psicodramática com crianças: uma proposta socionômica. São Paulo: Ágora.

Fleury, H. J., \& Marra, M. M. (2008). Grupos - Intervenção socioeducativa e método sociopsicodramático. São Paulo: Ágora.

Fonseca, J. (2012). Onde está o reconhecimento do ele na matriz de identidade? Intersecções entre Moreno e Lacan. Revista Brasileira de Psicodrama, 20(1), 115-134. Recuperado em 27 de outubro de 2018, de http://pepsic.bvsalud.org/scielo.php?script=sci_arttext\&pid=S0104$53932012000100009 \&$ Ing=pt\&tlng=pt

Freitas, M. A. L., \& Ferret, J. C. F. (2013). Práticas de intervenção em saúde mental na infância. VIII Encontro Internacional de Produção Cientifica CESUMAR. Maringá- PR. Anais eletrônico; Ed. Cesumar. Recuperado em 09 de dezembro de 2018, de http://www.cesumar.br/prppge/pesquisa/epcc2013/oit_mostra/Marina_Aparecida_Luiz_d e_Freitas2.pdf

Gonçalves, C. (1988). Psicodrama com crianças: uma psicoterapia possível. São Paulo: Ágora.

Halpern, R., \& Figueiras, A. C. M. (2004). Influências ambientais na saúde mental da criança. Jornal de Pediatria, 80(2, Supl.), 104-110. Doi: 10.1590/S002175572004000300013

Janiro, A. C; (2005). Caderno de atividades psicologia acessível. Campinas- SP. Recuperado em 15 de março de 2018, de https://psicologiaacessivel.net/caderno-deatividades-trabalhando-as-emocoes/

Manzini, E. J. (2001). Conceitos básicos em comunicação alternativa e suplementar. In: K. Carrara (org). Educação, Universidade e Pesquisa. (pp. 161-178). Marília: UnespMarília-Publicações, São Paulo: FAPESP.

Mental Health Atlas (2017). Geneva: World Health Organization; 2018. Licence: CC BY-NCSA 3.0 IGO. Recuperado em 15 de março de 2018 de http://apps.who.int/iris/bitstream/handle/10665/272735/9789241514019-eng.pdf?ua=1

Minayo, M. C. S. (2007). O desafio do conhecimento: pesquisa qualitativa em saúde. (10a. ed.). São Paulo: Hucitec.

Murta, S.; Gunther, I.; Guzzo, R. (2015). Prevenção e promoção em saúde mental no curso de vida: indicadores para ação. In: S. G. Murta, C. Leandro-França, K. B. Santos, \& L. Polejack (Eds). Prevenção e promoção em saúde mental . (pp. 75-92). Novo Hamburgo: Sinopsys.

Oliveira, M. A., \& Nakano, T. C. (2011). Revisão de pesquisas sobre criatividade e resiliência. Temas em Psicologia, 19(2), 467-479. Recuperado em 24 de janeiro de 2019, de http://pepsic.bvsalud.org/scielo.php?script=sci_arttext\&pid=S1413$389 \times 2011000200010 \&$ Ing $=$ pt\&tlng=pt

Phillipini, A. (2008). Cartografias da Coragem. Rio de Janeiro: Ed. Wak.

Ramalho, M. T. B. (2000). A brinquedoteca e o desenvolvimento infantil. Dissertação (Mestrado em Engenharia de Produção) - Universidade Federal de Santa Catarina, Florianópolis. 
Serrão, M.; Baleeiro, M. C. (1999). Aprendendo a ser e conviver. (2a.ed.). São Paulo: FTD.

Sinibaldi, B. (2013). Saúde mental infantil e atenção primária: relações possíveis. Revista de Psicologia da UNESP, 12(2), 61-72. Recuperado em 27 de outubro de 2018, de http://pepsic.bvsalud.org/scielo.php?script=sci_arttext\&pid=S198490442013000200005\&lng=pt\&tlng=pt.

Oaklander, V. (1980). Descobrindo crianças: a abordagem gestáltica com crianças e adolescentes. São Paulo: Summus.

Pachêco, M. V. G. M., Campos, C. N. A., Barbosa, L. N. F., Alves, J. S., \& Fernandes, J. R. (2017). Caracterização e perfil epidemiológico de um serviço de psiquiatria infantil no Recife. Revista da SBPH, 20(2), 136-152. Recuperado em 20 de janeiro de 2019, de http://pepsic.bvsalud.org/scielo.php?script=sci_arttext\&pid=S151608582017000200009\&lng=pt\&tlng=pt

Tartuce, T. J. A. (2008). Normas e técnicas para trabalhos acadêmicos. Fortaleza/CE: UNICE.

UNICEF. (2011). Situação mundial da infância 2011: adolescência, uma fase de oportunidades. Brasília, DF.

\section{NOTAS SOBRE AS AUTORAS:}

Lucyla Késia de Carvalho Silva - Mestranda em psicologia Clínica e Cultura (UnB).

E-mail: lucylakesia@gmail.com

Elisa Alves da Silva - Doutora em Psicologia Clínica e Cultura. Docente e coordenadora de Estágio do Curso de Psicologia da Faculdade Estácio de Sá de Goiás. E-mail: elisapsi@gmail.com 